\title{
Tales of science \& defiance: The case for co-learning and collaboration in bridging the science/emotion divide in water recycling debates
}

\author{
Although science is generally assumed to be well-integrated into rational \\ decision-making models, it can be used to destabilise consultative processes, \\ particularly when emotions are involved. Water policies are often seen as debates \\ over technical and engineering issues, but can be highly controversial. Recycled \\ water proposals in particular can create highly emotive conflicts. Through a case \\ study regarding the rejection of recycled water proposals in southeast \\ Queensland, Australia we explore the influence of science and emotions in \\ contemporary water planning. We highlight the dangers inherent in promoting \\ technical water planning issues at the expense of appropriate consideration of \\ citizen concerns. Combining the science-policy interface and stakeholder \\ engagement literatures, we advocate for collaborative decision-making processes \\ which accommodate emotions and value judgements. A more collaborative \\ stakeholder engagement model, founded on the principles of co-learning, has the \\ potential to broaden the decision-making base and to promote better and more \\ inclusive decision-making.
}

Keywords: scientisation; emotions; co-learning; recycled water; collaboration 


\section{Tales of Science \& Defiance: The case for co-learning and collaboration in bridging the science/emotion divide in water recycling}

debates

Edward Alexander Morgan $^{\mathrm{a}}$ and Deanna Chantal Cristina Grant-Smith ${ }^{\mathrm{b}}$

aUrban Research Program, School of Environment, Griffith University, Nathan, Australia

bSchool of Management, QUT Business School, Queensland University of Technology, Brisbane, Australia

\section{Introduction}

Increasing demand for a secure and safe supply of freshwater has combined with technological advances to shift thinking about the role of wastewater in water management and planning. Although technology now exists to transform wastewater into potable water to address water shortfalls, recycled water proposals remain controversial and public acceptance of recycled water remains a major obstacle to its adoption. Despite scientific assurances of the safety and purity of recycled water, alternatives such as desalinated water are generally publicly preferred (Marks 2006). Although there is some conditional public acceptance of the use of recycled water to water gardens and public green-spaces and supply power stations, even the indirect use of recycled water to augment existing water storages (such as reservoirs) before treatment in existing water supply systems remains unacceptable to many in Australia (Radcliffe 2010). Some scholars have suggested that this rejection cannot simply be assumed to be the result of a lack of knowledge or the need to reduce uncertainty (Ormerod and Scott 2013; Stenekes et al. 2006), and have called for improved public engagement and trust as vital components in realising public acceptance of a range of water governance proposals (Edwards 2009; Heazle et al 2013; Hurlimann and Dolnicar 2010). Such exhortations can fail to adequately account for the potential influence of 
negative emotions in water governance decision-making processes (Fishman 2011; Hartley 2006; Po et al. 2005; Russell and Lux 2009). This paper adds to the discussion by exploring how the conflict between science and emotion can add to the task of promoting recycled water alternatives and gaining the public and political support required to implement them.

Like environmental governance, water planning is an increasingly a scientised and technocratic domain. According to Bäckstrand (2004) this implies that political and social issues are best resolved by technical expert systems. Science, although generally assumed to be well-integrated into rational decision-making models, can work to destabilise consultative processes, particularly when emotions are involved, as has been seen in debates over issues like climate change and immunisation. Based on a case study of water governance issues in southeast Queensland, Australia, we discuss the difficulties of gaining public support for the implementation of emotionally volatile and politically controversial water proposals.

Drawing on the debates regarding recycled water proposals in the regional city of Toowoomba, Queensland and the insights of a wider research project into water governance in the region, we present a case for co-learning and collaborative approaches as a way to reconcile scientific and citizen contributions and accommodate emotions within decision-making processes. Past research has explored a range of factors associated with this case study including the impact of the media in shaping public opinion (van Vuuren 2009), the role of politics, vested interests, timing and information manipulation (Hurlimann and Dolnicar 2010) and the community’s attitudes to water (Fishman 2011). However, the combined influence of science and emotions in engagement processes are yet to be adequately explored. This paper asks 
how science and emotion can be better incorporated into the policy and planning process.

Through this case we highlight the dangers inherent in promoting scientific and technical solutions without appropriately integrating community concerns into consultative processes and argue that science and emotions need to be positioned as equally important factors in water planning debates. To achieve this, we advocate a decision-making and consultative process which makes space for emotions alongside science and provides opportunities for its productive expression by participants. We suggest that a more collaborative model of stakeholder engagement, founded on the principles of co-learning and the combination of scientific and other knowledges as an explicit strategy to bridge what we term the 'science-emotion divide', has the potential to broaden participation and to promote better and more inclusive decision-making. Such a reconsideration of the role of science in policy-making can also be understood as part of a broader agenda of better managing the interface between science and policy.

\section{Challenging the rational ideal of water policy}

The practice of governments making unilateral policy decisions-even when these decisions are seen to have satisfactory environmental, social and economic outcomesis no longer acceptable to the community or considered good practice by policy makers (Althaus, Bridgman and Davis 2007). Communities and other key stakeholders demand transparent and open decision-making and a direct role in the policy decisions that affect them. Policy-makers also recognise that implementing social and environmental policy change requires the active involvement and support of a wide array of stakeholders (Australian Government 2007). However, despite recognition of the complexity and political nature of policy making, the public and policy-makers alike expect, and often advocate for, policy-making input and decision-making data to be 
limited to expert scientific evidence. However, such rationalist approaches to policymaking can promote unrealistic public expectations and an over-reliance on technical expertise and engineering solutions (Heazle et al. 2013). Evidence-based policy approaches encourage the dismissal of values and emotions, substituting them with quantitative indicators as objective and rational evidence (Fischer 2003). Science is often promoted as the most appropriate source of such evidence and the most crucial and authoritative source of "neutral and factual input for crafting rational policies" (Bäckstrand 2004, 697).

This push toward policy informed by rigorously established objective evidence emphasises the importance of quantitative analysis and scientific data above experiential knowledges (Head 2009). This overt desire for neutral, value-free policymaking advocates processes which "keep emotion from creeping in where it does not belong” (Maroney 2006, 125) and elevates scientific knowledge to a pedestal. The danger of this scientisation of policy is that it implies that policy decisions should be based on science, with little (or ideally no) emphasis placed on values and emotions (Heazle 2010; Kellow 2007; Sarewitz 2004; Weingart 1999) and that political, social and environmental issues are better resolved by technocracy than democracy (Bäckstrand 2004). Many scholars suggest that the relationship between science and policy is not straightforward, and criticize the idea that science can speak truth to power as overly optimistic, and even naïve (Hoppe 2005; Jasanoff 1990; van Buuren and Edelenbos 2004). The resolution of environmental issues in particular presents a policy battleground where technocratic practice, which privileges scientific expertise, is pitted against democratic theory, which calls for the greater inclusion of the community in policy decisions (Bäckstrand 2004); unquestioned acceptance of scientific input may work to mask or crowd out the emotions that are an inherent a part of policy-making 
(Oreskes 2004). Using science to hide or run roughshod over values can inflame controversies (Sarewitz 2004) with the science itself becoming highly politicised and self-serving (Pielke Jr 2004). As Bäckstrand (2004, 705) notes “despite the aspiration to the objective and neutral ideal of science, scientific expertise is oftentimes pluralistic, divided, uncertain, contested and normative”. Indeed, as illustrated by recent debates over the nature, extent and causes of climate change, any acknowledged scientific uncertainty can become a target for political attack (Heazle 2010) with opponents seeking to promote different aspects of science, including the conflicting views of scientific experts. Science in this context is not a benign and apolitical policy input but rather a political weapon open to appropriation and deconstruction (Jasanoff 1990); science and how it is used can be influenced by a range of different factors, including values, the nature of the science, the governance arrangements and personal motivations (Morgan 2014). This paper responds to concerns that expectations that science can or should drive policy decisions, without due consideration of public input, is both unrealistic and likely to lead to conflict.

\section{Connecting collaborative approaches and the science-policy interface}

Pielke Jr (2007) and Turnhout et al. (2013) have identified a number of roles that scientists in policy-making. Through enacting these roles science has a number of applications within the policy process ranging from knowledge provision, arbitration, brokering, co-learning, to advocacy. Turnhout et al. (2013, p. 355) propose that these different roles “occupy different positions on a spectrum that represents the degree of interaction between knowledge producers and users that is considered appropriate in these roles”. For instance, knowledge provision requires limited interaction while co- 
learning requires more substantial and sustained interaction. ${ }^{1}$

Parallels can be drawn with models of stakeholder engagement (see Cameron and Grant-Smith 2014) which offer different levels of stakeholder participation in decision-making ranging from merely being informed through to collaboration based on partnership and dialogue (Figure 1). Within the context of water governance drawing an explicit connection between these models highlights the participatory and collaborative decision-making environment needed for social learning and co-learning to flourish and the means of achieving this (Baldwin et al. 2012; Blackmore 2007; PahlWostl et al. 2007). However, neither model adequate accounts for the potentially destabilising influence of emotions in what Jasanoff (1990) terms the co-production of knowledge.

\footnotetext{
${ }^{1}$ Advocacy is a common use of science, particuarly where there is conflict and controversy
} (Pielke Jr 2007; Sarweitz 2004), and can occur at any level of interaction. 


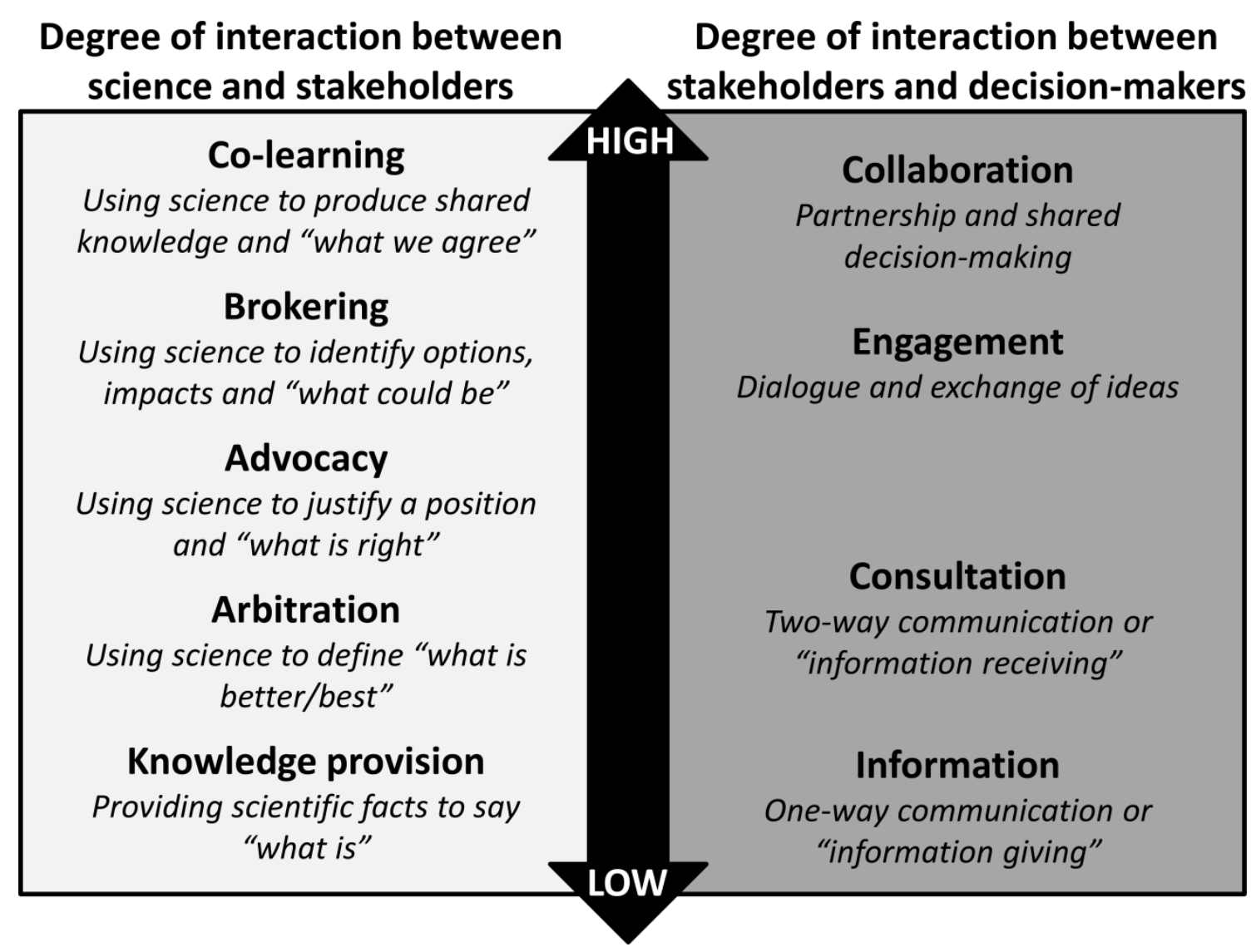

Figure 1: Comparing the science-policy interface with stakeholder engagement model.

\section{Research Approach}

This research focuses on the role of science and emotions in the creation of shared knowledge and understanding within water governance processes. While this paper focusses on recycled water in Toowoomba, the data reported were derived from a larger research project into water governance arrangements in southeast Queensland, Australia over the period 1990 to 2013. In total 22 semi-structured interviews were conducted in 2013 with current and former water managers, policy-makers, decision-makers, scientists and community campaigners (Table 1). Interview questions covered several major themes including current and planned water governance arrangements, engagement processes, and the use of science in water governance. Key policy documents, media reports, promotional materials, and secondary data (including books and research articles) were also analysed. 
The analysis here focuses on responses related to the influence of science and emotions in water governance decisions. Verbatim transcripts were manually coded according to Pielke Jr (2007) and Turnhout et al.'s (2013) typology of the use of science in policy and Cameron and Grant-Smith’s (2014) levels of stakeholder engagement. In particular, we searched for evidence that reflected: (1) tensions between the percieved and actual role of science in water governance decisions; (2) the extent to which existing engagement pratices are believed to accommodate emotional and scientific contributions; and (3) the potential for the integration of scientific and emotional contributions into water governance decision. This thematic analysis was supported by the use of NVivo.

Table 1: Details of interviewees

\begin{tabular}{|l|l|}
\hline Stakeholder type & Number of interviewees \\
\hline State government & $6^{*}$ \\
\hline Local and regional government & $6^{*}$ \\
\hline $\begin{array}{l}\text { Community and NGO groups } \\
\text { (including scientists) }\end{array}$ & 10 \\
\hline
\end{tabular}

*Includes both elected officials and public servants

\section{Science and defiance in securing Toowoomba's Water Future}

Over the last twenty years there has been a steady decline in the average rainfall over dam catchments across southern and southeast Queensland, Australia. With the exception of recent periods of extreme flooding it is believed that this may be the start of a persistent change from historical conditions, either under climate change or as part of long-term natural variability (Chiew et al. 2011). The prolonged drought conditions placed considerable pressure on the limited water resources on the city of Toowoomba region (Figure 2), located 120 kilometres west of Brisbane, which is reliant on dams as 
its primary water source. ${ }^{2}$

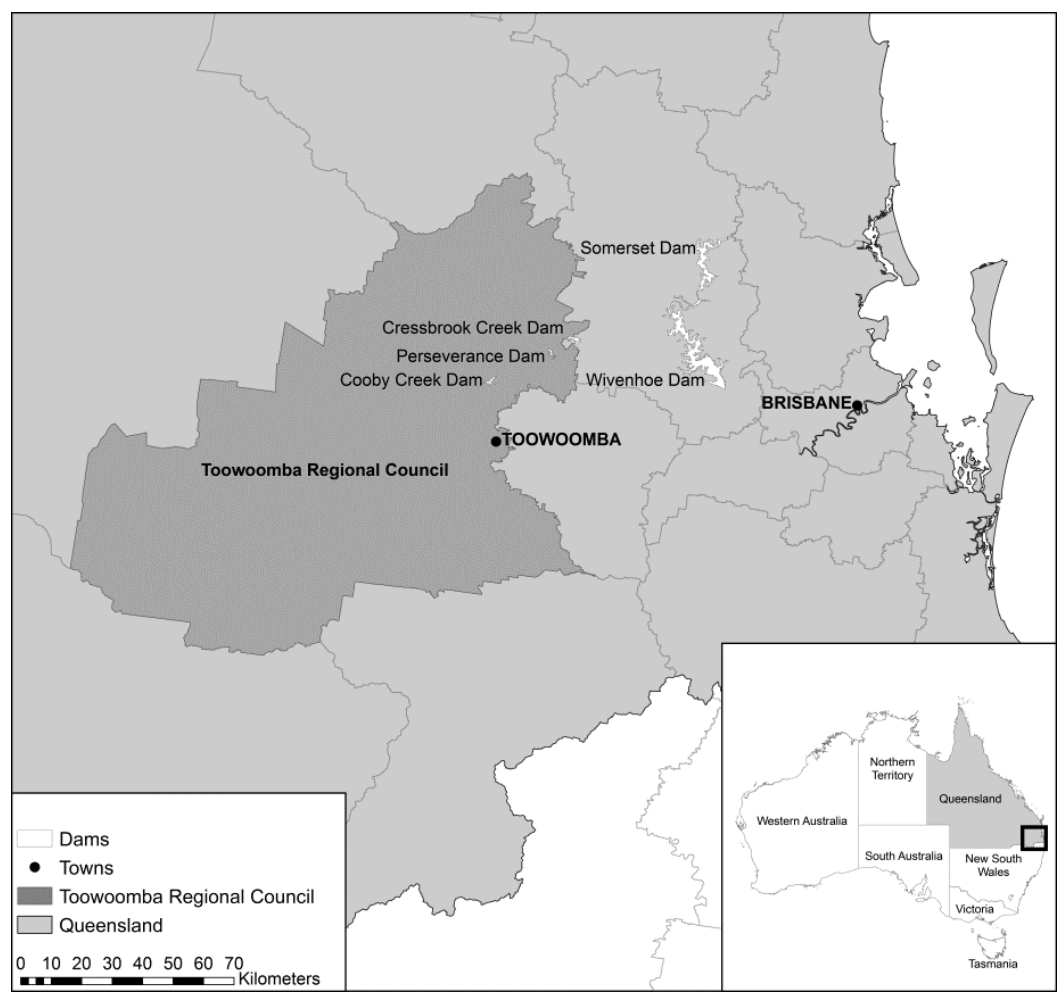

Figure 2: Map showing Toowoomba and major water storages.

As result of these climatic changes, in 2004 the Queensland government revised estimates of dam yields down. It advised that Toowoomba was exceeding its safe water yield (the amount that can be safely taken each year without dams and bores running dry) and forecast water shortages. In fact, Toowoomba had been exceeding its safe water yields for many years, but water use remained high (TCC 2006). In response to these concerns the state and local governments worked to identify and evaluate a wide range of options for ensuring water supplies into the future. This process was called Water Futures.

${ }^{2}$ Other water sources included bores and rainwater. In 2006 bore water contribution to Toowoomba's water supplies comprised between 10\% and 23.3\%. Rain water, from domestic rain water tanks, was only a minor supplement to water supplies (TCC 2006). 
Solutions considered under the Water Futures scheme included: behaviour change initiatives based on community education about water use and the introduction of domestic and commercial water restrictions; small-scale infrastructure initiatives (e.g. compulsory installation of rainwater tanks for all new buildings); and large-scale infrastructure responses such as upgrading pipes. While these water saving initiatives were adopted with few issues, measures to augment Toowoomba's water supplies were more problematic. Toowoomba's location far from the coast and atop a plateau meant that desalination and a pipeline to bring water from Wivenhoe Dam (the largest water reservoir in the region) were rejected as too costly, impractical and insecure. A new dam and increasing groundwater use were also assessed and rejected as inefficient and unsustainable. Consequently, the Council advanced a proposal to introduce recycled wastewater into municipal drinking water supplies through a planned indirect potable reuse scheme. The proposed process involved treating wastewater in an advanced water treatment plant that incorporated micro-filtration, reverse osmosis and ultraviolet disinfection/advanced oxidation technologies. The purified water was to be pumped into the existing Cooby Creek Dam, water from which was sent to a water treatment plant for normal treatment and mixed with (similarly treated) water from Cressbrook Creek and Perseverance Dams before entering Toowoomba's potable water system.

This proposal to introduce recycled wastewater into the city’s drinking water supplies proved highly controversial and divided the community, many of whom felt that the scheme was being forced upon the city with little or no consultation. Although the scheme had broad bi-partisan support from the majority of elected leaders from all three tiers of government-local, state and federal—opposition to the proposal by some community members became so strong that this support rapidly became muted, with some high profile elected officials turning against the proposals. As a result of this 
dissent, the Federal government resolved to tie its funding of the proposal to an expression of broad community acceptance through a referendum or formal plebiscite.

The Toowoomba City Council, led by charismatic mayor Di Thorley and backed (with varying degrees of vocality) by State and Federal politicians and the CSIRO (Commonwealth Scientific and Industrial Research Organisation), supported the proposals and worked to galvanise public support. A community-based No Campaign, led by locals, supported by a minority of councillors and funded by a millionaire property magnate, worked to enflame public dissent with the explicit aim of forcing the abandonment of the project. The issue was divisive and highly political, and the plebiscite meant it became a polarised question of yes and no, rather than a process of discussion, questioning and learning.

\section{Defiance: expressing irrational emotions or valid concerns?}

Those against the scheme, whatever their personal and political motivations, operated a highly emotive campaign (Fishman 2011; Hurlimann and Dolnicar 2010). These protesters unambiguously focussed their contributions on the prior sewage content of the wastewater and their disgust at being asked to 'drink sewage'. They forcefully signalled their dissatisfaction and disgust by forming a protest group called Citizens Against Drinking Sewage - CADS (Langford 2006). CADS and other opponents of the recycled water proposals called on the Toowoomba community to oppose the recycled water scheme. They raised potential health concerns and claimed that because removing all impurities was impossible the city and its residents were guinea pigs or lab rats for the untested technology (No Campaign 2006a, 2006b). They appealed to the community to reject the "toilet to tap" plan (Hanna 2006) and they argued that accepting recycled water could potentially have long term impacts on people’s view of Toowoomba, which they argued would become known as "POOwoomba” (Balderson 2006). In addition, 
voting no was promoted as a way of keeping the town's options for augmenting their diminishing water supplies open (No Campaign 2006a).

CADS and others launched high profile campaigns and invested in large scale letterbox drops. The emotion-laden images which featured prominently on these materials included a scared toddler with the caption “Mummy, I don’t want to die” and churning brown effluent in open sediment tanks at sewage treatment works (for examples see Ulm and Mate 2010). A council officer interviewed in this research noted that:

There were photographs on the internet of turds awaiting processing, as if to suggest that these things were going into a filter to produce recycled water...And the number of one-liners that you can get to support the no case is limitless. [They] kept talking about ‘drinking from the sewer'. (Local government 1).

The No Campaign invoked scepticism of science by exploiting uncertainty and the community's lack of understanding about the water recycling process (van Vuuren 2009), as well as the fear and disgust provoked by using sewage as the source of the water. Also, although it may have had less impact, the media potentially exacerbated division by emphasising the source of the water:

The media didn’t help. A media report about it would not show the water treatment plant which was producing drinking water, it would show our waste water treatment plant, and the huge expanses of big brown tanks. So that drove that percpetion all the time. Just little things like always referring to it as 'recycled sewage water'. (Local government 2).

\section{Science: deal maker, deal breaker or marginal player?}

In response to the emotive No Campaign, the Toowoomba City Council sponsored an extensive pro-recycled water campaign. As van Vuuren $(2009,62)$ observed "the proponents of the 'Yes' vote relied on the public's understanding of science, and 
capacity for rational debate, to make an informed decision”. Scientific claims in support of water recycling were made in the Water Futures plan (TCC 2006), brochures (Simpson 2006), formal council presentations, and on the council's website. The scientific concepts contained in these materials were presented using lay language and cartoons. For example, within the original Water Futures brochure the reverse osmosis process was illustrated using everyday objectives to represent equivalent sizes of chemicals, viruses and bacteria.

This scientific focus did have some drawbacks. Firstly, public perceptions of risk may have been heightened as a result of advocates’ inability to state with full scientific certainty that the recycled water would be 100\% pure (van Vuuren 2009); interviewees noted that some stakeholders were calling for “a 100\% guarantee that nothing will ever go wrong” (Local government 1). As a result the Yes Campaign focussed on the material process of treatment and the very low risks associated with recycled water. Secondly, expert information was reified and there was little opportunity for it to be considered as another narrative in the controversy or space for alternative knowledges to be considered (Hampton 2009).

In addition to employing arguments based on science, advocates also appealed to economic arguments based on cost-benefit analysis. This focus on science and economic analysis reflected a desire for the decision to be based on facts; in this context a 'no vote' was seen to be an irrational and ill-informed choice based on a lack of knowledge, rather than legitimate social, cultural or scientific concerns. Such a view is exemplified in public comments made by Malcolm Turnbull MP, the then Federal Parliamentary Secretary with special responsibility for water, who noted:

This 'Poowoomba' thing is ludicrous, it's childish and it's only being promoted by those people on the 'no' side. (Lateline, 28/07/2006) 
According to Price, Fielding and Leviston (2012, 986) proponents “didn’t see the Yes campaign as appealing to emotions”, rather it was concerned with facts and reason. Such a view of the irrationality of opposition was mirrored by the then Queensland Premier, Peter Beattie, who announced that in the event of a no vote the State government would "have to go out and explain the truth about [wastewater] recycling” (quoted in Langford 2006). Such views are still held by those in favour of recycled alternatives, as demonstrated by the views of a council officer who suggested that a lack of understanding of the science of recycled water allowed the referendum to be hijacked by personalities:

\footnotetext{
And even though council was continually putting forward what we saw as the facts and the science, if they [the public] couldn't understand the science it came down to a question of what they were being told. Who would they trust more? Was it the people representing the 'No case', and they knew a lot of those personalities and they had for decades. Or council, who has a PR problem generally. (Local Government 2)
}

While technical and scientific experts were used to strengthen the case for recycled water, experts and the lay public had little opportunity for constructive interaction. Faced with a decision which required detailed and scientific knowledge, van Vuuren (2009) argues that many community members may have found it is easier to suspend their own judgement and to look to trusted opinion leaders they believed shared their values. Furthermore, because the various stakeholders “did not engage in constructive dialogue on the issue of a long-term potable water supply...the debate on which the decision was based on was limited and divisive” (Hampton 2009, 229).

\section{Science vs. Emotion: only one winner?}

Although late polling indicated majority support, when the referendum was conducted 
on 29 July 2007 almost two-thirds (62\%) of voters voted no to government plans to supplement their drinking water supply with treated recycled wastewater (Price et al. 2012, 984). In response to the referendum result, Malcolm Turnbull MP proposed that "the no case has obviously been a scare campaign...based more on emotion rather than science” (Millar 2006). Proponents were clearly disappointed with the result and lamented the extent of the influence of emotional appeals and vested interests rather than scientific fact in shaping public opinion on the recycled water proposal (Phillips 2006). They felt the science had been ignored due to the emotive nature of the No Campaign:

It would be nice to think the science would underlay the decison. Unfortunately in this case and I suspect in quite a few cases in the future science is going to take second place to the emotion and the marketing. (Local Govenrment 2)

Following the referendum result, the State and local government funded and constructed a pipeline from Wivenhoe Dam to Toowoomba at a construction cost of AU\$187 million. The pipeline, completed in January 2010, cost Toowoomba ratepayers an estimated AU\$112 million (Anonymous 2011). ${ }^{3}$

Nonetheless, Toowoomba residents have proven themselves willing and able to change their water use habits. Unpublished council records provided during our interviews record that domestic consumption has fallen from nearly $250 \mathrm{~L} /$ person/day in late 2004 and 2005 to less than 150 L/person/day from 2008 onwards (Toowoomba Regional Council, 2013). Toowoomba residents embraced measures to shift domestic

\footnotetext{
${ }^{3}$ The remaining $\$ 75$ million was provided by the Queensland Government. In contrast, independent engineers estimated the cost of the recycling scheme would be in the ballpark of AU\$68 million, \$18 million of which would have been funded by ratepayers
} (Anonymous 2011). 
water consumption practices through a combination of behaviour change and smallscale infrastructure measures (e.g. residential water tanks and water saving devices). While mandatory water restrictions elsewhere in the region have been relaxed (Thompson and Solomons 2012), the city has codifed its restriction of $200 \mathrm{~L} /$ person/day as a permanent water conservation measures (Figure 3), and water consumption has remained low even though recent years have seen flooding in the region and reservoirs are now virtually full. However, another serious drought could dam levels, and the existing policy to supplement Wivenhoe Dam with recycled water if it falls below $40 \%$ capacity (Johnstone 2009) may see the citizens of Toowoomba end up with recycled water in their supply.

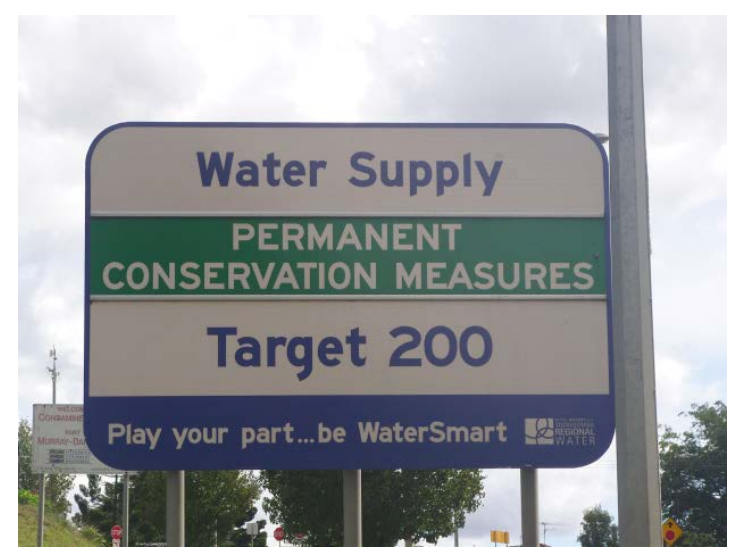

Figure 3: 'WaterSmart' road sign on the western approach to Toowoomba city (photo: Edward Morgan).

\section{Revisiting the role of science and emotions in water planning: what can we learn from Toowoomba?}

Many critiques of failed water recycling proposals highlight the importance of improved public consultation (Hurlimann and Dolnicar 2010; Ormerod and Scott, 2013; Stenekes 2006). While it is difficult to refute such claims, a lacuna in these approaches is that they tend to conflate education, primarily based on the provision of scientific information, and consultation. Furthermore, they can fail to recognise the powerful 
influence that emotions can have in consultative processes. The remainder of this paper explores the potential for a more collaborative model of stakeholder engagement, founded on the principles of co-learning and the co-production of scientific and other knowledges, to broaden the decision-making base and promote better and more inclusive decision-making.

\section{Accounting for emotions in water planning}

It has been argued that the main reason that recycled water is more likely to be rejected than other recycled products is that the source of recycled water, sewage, elicits considerably more disgust and negative emotional responses than the source materials of recycled paper or plastic containers (Mellon and Tsagarakis 2006). As one interviewee noted:

It was there with toilet paper and baby's bottles and all that sort of shit which was the fear thing cos everything's driven by fear...And that's people's absolute fear of their own bloody shit and pee. That absolute fear. (Local government 3).

This ‘yuck' factor has been recognised as making a significant contribution to people’s responses to wastewater recycling and sewage management proposals, and is arguably the largest barrier to community acceptance of recycled water (Fishman 2011; Hartley 2006; Po et al. 2005; Russell and Lux 2009). Community perceptions of water recycling are sensitive (Mikhailovich 2009) and responses to recycled water proposals can be highly emotional, particularly when images of drinking excrement come into play (Schäfer and Beder 2006). The success of campaigns against recycling schemes which exploit the yuck factor (through images of 'toilet-to-tap' and 'sewage beverage') in both Australia and the US (Grant-Smith 2011; Hartley 2006; Po et al. 2005)—starkly exemplified in Toowoomba-highlight the fact that emotional responses to sewage need to be considered to fully understand and respond to community concerns about 
wastewater recycling (Khan and Gerrard 2006). Certainly the yuck factor was a significant influence on the opinions of opponents. However, it should be noted that the use of emotive aspects are not limited to the yuck factor-the Yes Campaign emphasised fears of running out of water-and both sides of the debate "felt that the other was emotive, derogatory, and better resourced” (Price et al. 2012, 987)

Despite the obvious influence that these so-called irrational concerns about the sewage content of recycled water have on the public acceptance of such proposals, many researchers focus on rational explanations to account for their rejection. Some point to the impact of a lack of knowledge and understanding of proposals by the public (Gibson and Apostolidis 2001), the media (Goodman and Goodman 2006) or elected officials (Ingram et al. 2006), or socio-demographic factors such as gender or education levels (Miller and Buys 2008; Po et al. 2006). Others focus on the impact of trust (Edwards 2009; Marks and Zadoroznyj 2005; Schäfer and Beder 2006) and public perceptions of the credibility, fairness and respect of authorities proposing the introduction of recycled water (Beecher et al. 2005). Some suggest that a lack of appropriate consultation on proposals (Marks 2006), and the absence of a common language, shared understandings and opportunities for social learning (Baggett et al. 2006) exacerbate tensions.

As a result, the solutions to the complex issues of public and stakeholder opinion that underlie recycled water debates focus on two broad tactics. Firstly, the need for appropriate education, persuasion and public relations techniques to develop public understanding (Friend and Coutts 2006; Gibson and Apostolidis 2001). Secondly, the need for enhanced consultation, deliberation and trust building opportunities (Beecher et al. 2005; Edwards 2009; Marks 2006; Russell and Hampton 2006; Russell and Lux 2009). 
We agree that consultation has a clear role to play in allowing for meaningful public debate on a wide range of water planning issues. However, while this growing body of work broadly recognises the role that cultural norms, psychological factors and emotional responses play in the adoption of recycled water schemes in general, it often does not deal in any substantial way with the inclusion of emotions in decision-making. We argue that designing processes which pay attention to the emotional content of stakeholder contributions and the apparent conflict with science can help in creating 'better' consultation.

Before the imposition of the plebiscite the council had planned a three year communication program (Thorley 2007), however, there is no evidence that this program would have addressed emotional concerns. Indeed, extant Council promotional materials focus heavily on the technical issues (e.g. TCC 2006). Part of the reason for this technical focus may have been a perceived need for expediency and educating the public about the 'facts'. In the midst of a long running drought Toowoomba was running out of water. The significant time pressure associated with supply concerns impacted on the ability to consult widely and led to a decision to rely on persuasion through science, demonstration and education rather than consultation.

I remember [someone] coming up to Toowoomba and saying to me, you just don't understand how to do community consultation. And I said, you know, well there really actually comes a time you got to drop the dozer blade. And we were down to eight percent. (Local government 3)

Council's planned process

[It] was essentially a three year public education program. It wasn't consultation in the sense that we didn't go to them and first ask them what they wanted...But because we found ourselves in the situation we did, this whole thing had to be 
squeezed into a very limited period under very intense opposition. (Local government 1)

The decision to implement a plebiscite further limited opportunities for meaningful consultation.

In their efforts at educating the public, proponents focussed almost exclusively on the technical, scientific and infrastructure issues associated with the management and regulation of recycled water:

Then there was the 'yes' case and the 'no' case and the ultimate polarisation. Of course council was out there spear-heading the case for the science. There was the no case out there referring to other things. (Local government 2).

There was an effort to routinely write emotions out of these stories about recycled water and to replace them with a focus on treatment regimes and the science and technology of water recycling. Those questioning the science and technology were seen as contributing little more to the debate than an uninformed, uneducated nuisance based on irrational and unsophisticated emotions such as fear and disgust, as described by one elected official: "Fear. Fear. Driven by people with their own agenda, the fear. Science went out the back door.” (Local government 3)

The problem with this is that fears in relation to recycled water are not easily allayed by abstracted science or the assurances of politicians. The public acceptance of technical facts regarding recycle water depends upon on trust in institutions (Ormerod and Scott 2013). However, many Toowoomba citizens felt that there was a lack of transparency in the council's handling of the issue and the debate. Fishman $(2011,154)$ notes that members of the No Campaign were critical of what they perceived to be a lack of consultation and debate and the Mayor's insistence “the city's staff, scientists, and leadership had considered all the water options, and this was the only viable one”. 
Council’s perceived failure to respond to concerns left some community members wondering what they weren't being told (Turner 2006). As the interviewees in this research noted, this is likely to have impacted on trust in the council's ability to make decisions in the best interest of the community.

It is important to note that neither side of the debate had exclusive access to truth nor exclusive claims to rationality; both derided the emotional content of each other's contributions while exploiting the power of emotions to advocate their own position. Promoting fears of running out of water may not have had the proponents' desired influence on the outcome of the recycled water referendum, but they were highly successful in driving down water usage, and community anger at residents using more than their fair share resulted in public involvement in informal policing and managing of the restrictions (Hurlimann and Dolnicar 2010; Turner 2006). This community participation has been noted as an important factor in achieving long term behaviour change in water usage in the region (Walton and Hume 2011). It also speaks to the importance of finding ways to incorporate value judgements and beliefs that go beyond scientific information in decision-making processes if water planning initiatives are to be sustainable (Bengtsson and Tillman 2004; Stenekes 2006) .

\section{Recognising the limitations and strengths of science in policy-making}

The community response to the recycled water proposal has shown that it is not enough to simply propose new technological and infrastructure solutions and to provide scientific justifications for these. As Peter Spearitt $(2008,25)$ notes: “a vast scientific effort mounted in favour of the 'Yes' vote proved to be of no avail”. Instead there also needs to be a focus on understanding and responding to community values and emotions. However, finding a place for values and emotions alongside scientific contribution when decision-making is highly scientised can be challenging. Improved 
participatory approaches can enable the interaction between public values and scientific knowledge and assist in the broader decision-making process by allowing scientists "to work with public values and address public concerns in their provision of information” (Hampton 2009, 237).

The council made use of scientific information in an arbitration and brokering capacity to inform decision-making around the identification of options and their likely costs and benefits. This willingness to use science in an advisory or consultative capacity allowed concerns about the quality and safety of recycled water to be raised and discussed. As one elected official noted:

You are supposedly eight good true people sitting around a table with a modicum of common-sense that is going to seek expert help and advice, put some commonsense in it and come out with a bloody good solution. No matter what it is, all we have to do is depend on expert advice. (Local government 4)

Adopting this discursive and consultative approach resulted in the majority of the council initially voting in favour of recycled water. However, in interactions with the community and other external stakeholders, science was relegated to a knowledge provision role to educate the community about recycled water and an advocacy role to promote the strengths of the proposal. In large part the role of science was to promote what were perceived to be rational choices and to override what were considered to be inappropriately emotive opposition, and to address a perceived knowledge deficit within the community about the recycled water process.

Attempting to use science to challenge values and emotions, without engaging in a process which provides for the expression and discussion of a range of issues, is unlikely to result in positive outcomes. Use of science in knowledge provision can bring with it the assumption that science provides the objectively right answer and there is no need for emotion (but the emotive nature of the issue meant the knowledge was not 
trusted or believed), while use of science in advocacy hides any personal motivations, emotions or values behind the scientific arguments (the council decision was as much economic and political as scientific). This allowed the science to become the focus of the debate, even though it was as much about politics, emotions and attitudes to water. Privileging rationalistic scientific knowledge limits participation and expression, and also "mitigates against the adoption of a diversity of contestation; whereby individuals can protest about and involve themselves in policy formulation” (Eden 1996, 196).

The greater the level of risk if a wrong decision is made and the greater the complexity of the problem, the more important it is that decision-making processes founded on principles of engagement or collaboration are adopted (Cameron and GrantSmith 2014). Although the actual hazard posed by recycled water may have been argued to be small, it was perceived as high risk by the community. As a result high levels of participation are likely to be important, a point reflected in the calls for more and better consultation discussed above. However, restricting the use of science to an advocacy and knowledge provision capacity can limit this participation. As one community campaigner noted:

\footnotetext{
We've just got to recognise what we are dealing with in society. The science has to be there, it has to be right, I'm not saying go with dodgy science, but just having the science nailed you're nowhere... if you want change, that's not enough, you need a whole social element, you need an economic element and you need a political element. (Community campaigner 1)
}

Using science in a co-learning capacity as part of a broader collaborative process may have provided a space for co-producing shared understanding through a process of social learning and open deliberation. Embedding co-learning within more collaborative decision-making approaches also allows the development of a shared language to discuss issues and for the emotional expression of what must be recognised as 
legitimate concerns. Such community engagement has the potential to contribute to the legitimacy of decision-making processes and to identify alternatives that may not have otherwise been considered (Ormerod and Scott 2013). While a focus on technical issues is likely to lead to exclusion, this kind of creative engagement opens up other pathways to sustainability other than the technocratic (Stenekes 2006) by offering the opportunity to develop and test one's own opinions.

\section{The potential for co-learning and collaboration to bridge the science/emotion divide}

Despite the obvious benefits, creating opportunities for collaboration and co-learning can be difficult, particularly when dealing with highly political and controversial issues. However, allowing emotion to be part of these debates may work to encourage higher levels of participation and engagement by providing permission for people to express a wider range of views. A willingness to embrace, for example, emotions like disgust may actually help people to confront them and find ways of working through them. We have identified three potential considerations for adopting a more collaborative model of stakeholder engagement founded on the principles of co-learning and the co-production of scientific and other knowledges in future water planning endeavours.

Firstly, the development of a shared language is needed to allow discussion of the otherwise unspeakable (Grant-Smith 2011). In order to accept emotion into the policy process, policy-makers must be willing to allow a shared/hybrid language to develop, which accommodates difference and emotions and established the legitimacy and credibility of all participants. Such a collaborative co-learning environment would require the acceptance of a broader range of non-scientific and non-technical contributions and necessarily the tolerance of emotional language and concerns. Technical and scientific contributions would continue to be valued, but not privileged or 
treated as automatically the right or only answer. Proponents of water recycling may have been unwilling to discuss the fact that current water storages are exposed to 'disgusting' things, such as animal faeces and carcasses based on concerns that residents may lose faith in current water treatment systems. However, a willingness of both sides to openly discuss the disgusting may have robbed it of some of its power in the debate.

Secondly, science could be allowed greater freedom to be 'less technical' and alienating. As part of a participatory process, with science considered equal to other knowledges, scientists/experts could be given the freedom to generalise and express uncertainty, without it being criticised or dismissed. Science, used in this way, could provide the starting point for discussions and broaden the debate around what is possible. Because public trust in science and scientists remains high, this trust could be used to lead discussions, provided that the science can be understood as part of a colearning process, rather than providing knowledge to educate or one-size-fits-all solutions.

Finally, there may be opportunities to move beyond using science in advocacy toward co-learning by providing deliberative spaces which increase interaction between stakeholders. Advocacy is an inevitable part of any policy process, but limiting science to an advocacy role can result in knowledge fights where coalitions form and stabilise around particular values and produces their own knowledge to attack each other (van Buuren 2004). Interaction between the stakeholders (and with the science) is likely to be high within a coalition, but very limited between coalitions. Hence, while these coalitions provide a protected space that can allow marginalised groups to develop a response to issues, it is only by bringing these coalitions together that transformative changes to values can occur (Cameron and Grant Smith 2005). Providing a deliberative space which brings conflicting coalitions of stakeholders together might better direct 
consultation efforts and avoid simply reinforcing existing coalitions. Interestingly, shared emotions (such as disgust) may provide the coordinating mechanism to bring coalitions together. Such an approach provides a way to direct 'advocacy' efforts away from arguments about technical issues towards debate and the productive exchange of ideas, and encourage an exploration of why one group is willing to accept recycled water while another isn't.

\section{Conclusion}

Despite increasing recognition of the need to include multiple perspectives in water planning decisions there are still calls to elevate contributions which are considered to be "rational and dispassionate” (Ching 2010, 123). The very idea that scientific knowledge is incompatible with emotional contributions needs to be contested (Ahmed 2004, 82) because it presupposes that scientific contributions are more valuable and less partisan. Science and emotion both have a key role to play in policy-making, especially in controversial issues. This is not restricted to water governance planning issues such as recycled water which involve emotive and unspeakable objects (Grant-Smith 2011). Many other planning processes face similar problems such as the controversies around planning for renewable energy using wind farms (Cass and Walker 2009). The quest for rational policy-making urges emotion to be removed, which is at best unrealistic and at worst dangerous. As the controversy around recycled water in Toowoomba highlights, emotion and science are an equally important part of water planning. Science has a central place in co-learning and collaborative decision-making to help to generate new solutions, but not simply as a tool to present uncontested fact and as the antithesis of emotional contributions. Allowing emotion in to the debate, indeed reserving a place for it, can facilitate this process of co-learning and collaboration. Furthermore, co-learning and collaboration should be seen as an investment not an impediment to decision- 
making and emotions as an adjunct to science not its nemesis. Embracing emotions in policy-making involves some risk, but it also provides myriad opportunities. Despite the conflicts over water recycling, Toowoomba has become a town that prides itself on its water conservation measures and low water consumption and has taken some steps to securing its water future, even without recycled water. Allowing science and emotion to work together in a collaborative, co-learning process to help resolve future water crises can facilitate this journey.

\section{Acknowledgements}

The authors would like to thank the interview participants in this research and the anonymous reviewers of this article. E.A. Morgan would like to thank Dr Karen Vella and Dr Michael Howes for useful discussions.

\section{References}

Ahmed, S. (2004) The Cultural Politics of Emotion. Edinburgh University Press, Edinburgh.

Althaus, C., Bridgman, P. and Davis, G. (2007) The Australian Policy Handbook. $4^{\text {th }}$ edition. Allen and Unwin: Sydney.

Anonymous. (2011) Recycled water poll: five years on. The Chronicle. 13th August 2011. http://www.thechronicle.com.au/news/toowoomba-recycled-water-pollfive-years-later/1066451/

Australian Government. (2007) Best Practice Regulation Handbook. Office of Best Practice Regulation, Commonwealth of Australia: Canberra.

Bäckstrand, K. (2004) Scientisation vs. civic expertise in environmental governance: eco-feminist, eco-modern and post-modern responses. Environmental Politics, 13(4): 695-714.

Baggett, S., Jeffrey, P. and Jefferson, B. (2006) Risk perception in participatory planning for water reuse, Desalination, 187: 149-158. 
Balderson, S. (2006) Anti-recycling campaigners voice their defiance, The Chronicle, 29 May 2006. Available from: http://www.thechronicle.com.au/news/apn-antirecycling-campaigners-voice-thei/3380/

Baldwin, C., Tan, P.-L., White, I., Hoverman, S., Burry, K., (2012) How scientific knowledge informs community understanding of groundwater, Journal of Hydrology, 474: 74-83.

Beecher, N., Harrison, E., Goldstein, N., McDaniel, M., Field, P. and Susskind. L. (2005) Risk perception, risk communication and stakeholder involvement for biosolids management and research, Journal of Environmental Quality, 34: 122128.

Blackmore, C. (2007) What kinds of knowledge, knowing and learning are required for addressing resource dilemmas?: a theoretical overview, Environmental Science \& Policy, 10(6): 512-525.

Bengtsson, M. and Tillman, A. (2004) Actors and interpretations in an environmental controversy: the Swedish debate on sewage sludge use in agriculture, Resources, Conservation and Recycling, 42: 65-82.

Cass, N. and Walker, G. (2009) Emotion and rationality: The characterisation and evaluation of opposition to renewable energy projects, Emotion, Space and Society, 2: 62-69.

Cameron, J. and Grant-Smith, D. (2005) Building citizens: participatory planning practice and a transformative politics of difference, Urban Policy and Research, 23: $21-36$

Cameron, J. and Grant-Smith, D. (2014) Putting people in planning: participatory planning, inclusion and power, in Australian Environmental Planning: Challenges and Future Prospects, ed. Byrne J., Dodson, J. and Sipe N., Routledge, London, pp. 197-205

Chiew, F. H. S., Young, W. J., Cai, W. and Teng, J. (2011) Current drought and future hydroclimate projections in southeast Australia and implications for water resources management. Stochastic Environmental Research and Risk Assessment, 25(4): 601-612.

Ching, L. (2010) Eliminating 'yuck': a simple exposition of media and social change in water reuse policies. International Journal of Water Resources Development, 26(1): 111-124. 
Eden, S. (1996) Public participation in environmental policy: considering scientific, counter-scientific and non-scientific contributions, Public Understanding of Science, 5: 183-204.

Edwards, P. (2009) Trust, Power and Engagement: Participatory Water Planning on the Gold Coast, Australia. PhD Thesis, Griffith University, Australia.

Fishman, C. (2011) The Big Thirst: The Secret Life and Turbulent Future of Water, Free Press, New York.

Fischer, F. (2003) Reframing Public Policy: discursive politics and deliberative practices, Oxford University Press: Oxford.

Friend, H. D. and Coutts, S. S. (2006) Achieving sustainable recycled water initiatives through public participation, Desalination, 187: 159-166.

Gibson, H. E. and Apostolidis, N. (2001) Demonstration, the solution to successful community acceptance of water recycling, Water science and technology: a journal of the International Association on Water Pollution Research, 43: 259266.

Goodman, J.R. and Goodman, B.P. (2006) Beneficial or biohazard? How the media frame biosolids, Public Understanding of Science, 15: 359-375.

Grant-Smith, D. (2011) More than merely wicked: regulating sewage discharges and other unspeakable problems in environmental policy-making and planning. Presented at Wicked Problems: Environmental Research Event 2011, 26-29 June 2011, Moreton Bay Research Station, North Stradbroke Island. Available from: http://eprints.qut.edu.au/63452/

Hampton, G. (2009) Narrative policy analysis and the integration of public involvement in decision making. Policy Sciences, 42(3): 227-242.

Hanna, C. (2006) Fears will wash away with time, Queensland Times, (Ipswich edition), 1 August 2006.

Hartley, T. (2006) Public perception and participation in water reuse, Desalination, 187: $115-126$.

Head, B. (2009) Evidence-based policy: principles and requirements. In: Strengthening Evidence-Based Policy in the Australian Federation. Volume 1: Roundtable Proceedings. 17-18 August 2009, Productivity Commission: Canberra.

Heazle, M. (2010) Uncertainty in policy making: Values and evidence in complex decisions, Earthscan, London. 
Heazle, M., Tangney, P., Burton, P., Howes, M., Grant-Smith, D., Reis, K. and Bosomworth, K. (2013) Mainstreaming climate change adaption: An incremental approach to disaster risk management in Australia. Environmental Science \& Policy, 33: 162-170.

Hoppe, R. (2005) Rethinking the science-policy nexus: from knowledge utilization and science technology studies to types of boundary arrangements, Poiesis \& Praxis, 3: 199-215. Available from: 10.1007/s10202-005-0074-0.

Hurlimann, A. and Dolnicar, S. (2010) When public opposition defeats alternative water projects - the case of Toowoomba Australia., Water research, 44: 287-297. Available from: 10.1016/j.watres.2009.09.020.

Ingram, P.C., Young, V.J., Millan, M., Chang, C. and Tabucchi, T. (2006) From controversy to consensus: the Redwood City recycled water experience, Desalination, 187: 179-790.

Jasanoff, S. (1990) The Fifth Branch: Science Advisors as Policymakers, Cambridge, MA: Harvard University Press.

Johnstone, C. (2009) Water recycling pipeline in mothballs, Courier Mail, 8 May, 2009. Available from: http://www.couriermail.com.au/news/queensland/recyclepipeline-in-mothballs/story-e6freoof-1225710435782.

Kellow, A. (2007) Science and Public Policy, Cheltenham, UK: Edward Elgar Publishing.

Khan, S. J. and Gerrard, L. E. (2006) Stakeholder communication for successful water reuse operations, Desalination, 187: 191-202.

Langford, R. (2006) Toowoomba Says No, The Courier Mail, 29 July 2006. http://www.couriermail.com.au/news/special-features/toowoomba-saysno/story-e6freoyo-1111112143990?nk=c198039dbe6f98654190706648035137

Marks, J. (2006) Taking the public seriously: the case of potable and non potable reuse, Desalination, 187: 137-147.

Marks, J. and Zadoroznyj, M. (2005) Managing sustainable urban water reuse: structural context and cultures of trust, Society and Natural Resources, 18: 557572.

Maroney, T. A. (2006) Law and emotion: a proposed taxonomy of an emerging field, Law and Human Behaviour, 30: 119-142. 
Mellon, R. C. and Tsagarakis, K. P. (2006) Assessment of implicit meaning in the design of graphic symbols for the control of recycled water use, Environment and Behavior, 38(5): 689-706.

Mikhailovich, K. (2009) Wicked water: engaging with communities in complex conversations about water recycling, EcoHealth, 6: 324-330.

Millar, L. (2006) Poowoomba: Turnbull supports treated sewage water [transcript], AM Program ABC radio, 29 July 2006. Available from: www.abc.net.au/am/content/2006/s1700353.htm.

Miller, E. and Buys, L. (2008) Water-recycling in South-East Queensland, Australia: what do men and women think? Rural Society, 18(3): 220-229.

Morgan, E. (2014) Science in Sustainability: A Theoretical Framework for Understanding the Science-Policy Interface in Sustainable Water Resource Management, The International Journal of Sustainability Policy and Practice, 9: $37-54$.

No Campaign. (2006a) Toowoomba Decides, No Campiagn Advertisment, July 2006, authorised by C. Berghofer. Available from: http://www.valscan.com.au/webpaper.pdf

No Campaign. (2006b) Think before you drink, No Campaign booklet, authorised by S. Manners and J. Dowson. Available from: http://www.valscan.com.au/tbyatdBris.pdf

Ormerod, K. J. and Scott, C. A. (2013) Drinking Wastewater: Public Trust in Potable Reuse, Science Technology Human Values, 38: 351-373.

Oreskes, N. (2004) Science and public policy: what's proof got to do with it?, Environmental Science \& Policy, 7: 369-383.

Pahl-Wostl, C., Craps, M., Dewulf, A., Mostert, E., Tabara, D., Taillieu, T. (2007) Social learning and water resources management, Ecology And Society, 12(2): 5.

Pielke Jr, R. A. (2004) When scientists politicize science: making sense of controversy over The Skeptical Environmentalist, Environmental Science \& Policy, 7: 405417.

Pielke Jr, R. A. (2007) The Honest Broker: Making Sense of Science in Policy and Politics, Cambridge University Press: Cambridge.

Phillips, S. (2006) Thirsty Australian town rejects plan to drink recycled sewage, COSMOS Magazine, 31 July 2006. 
http://www.cosmosmagazine.com/news/thirsty-australian-town-rejects-plandrink-recycled-sewage/

Po, M., Nancarrow, B.E., Leviston, Z., Porter, N.B., Syme, G.J. and Kaercher, J.D. (2005) Predicting community behaviour in relation to wastewater reuse: what drives decisions to accept or reject?, Water for a healthy country national research flagship, CSIRO Land and Water, Perth.

Price, J., Fielding, K. and Leviston, Z. (2012) Supporters and opponents of potable recycled water: culture and cognition in the Toowoomba referendum. Society and Natural Resources: An International Journal, 25(10); 980-995.

Radcliffe, J. (2010) Evolution of water recycling in Australian cities since 2003, Water Science and Technology: A Journal of the International Association on Water Pollution Research, 62(4), 792-802

Russell, S. and Hampton, G. (2006) Challenges in understanding public responses and providing effective public consultation on water reuse, Desalination, 187: 215227.

Russell, S. and Lux, C. (2009) Getting over yuck: moving from psychological to cultural and sociocultural analyses of responses to water recycling, Water Policy, 11: 21-35.

Sarewitz, D. R. (2004) How science makes environmental controversies worse, Environmental Science \& Policy, 7: 385-403.

Schäfer, A. and Beder, S. (2006) Relevance of the precautionary principle in water recycling, Desalination, 187: 241-252.

Simpson, J. (2006) From waste-d-water to pure water, Jennifer Simpson, Woombye. Available from:

http://www.watersecure.com.au/pub/images/stories/other_publications/From_wa ste_d_water_to_pure_water.pdf

Spearitt, P. (2008) The water crisis in Southeast Queensland : How desalination turned the region into carbon emission heaven, in Troubled waters: Confronting the water crisis in Australia's cities, ed. P. Troy, ANU EPress, Canberra, pp. 19-36.

Stenekes, N., Colebatch, H. K., Waite, T. D. and Ashbolt, N. J. (2006) Risk and governance in water recycling: public acceptance revisited, Science, Technology and Human Values, 31(2): 107-134. 
Thompson, T. and Solomons, M. (2012) Water Relief. LNP will turn the taps back on to boost revenues, Courier Mail, 15 October 2012. http://www.news.com.au/national/newman-government-turns-taps-back-on-toraise-cash/story-e6frfkp9-1226495841394

Thorley, D. (2007) Toowoomba recycled water poll, Reform, 89: 49-51

Toowoomba City Council (TCC). (2006) Water Futures Toowoomba: securing a safe and sustainable supply of water for our future. Toowoomba City Council, Toowoomba.

Toowoomba Regional Council. (2013) Domestic water use consumption data, $6^{\text {th }}$ August 2013 (unpublished report).

Turner, B. (2006) Transitional fears: water, surveillance and the abject in Australia, paper presented at the Cultural Studies Association of Australia Annual Conference, University of Canberra, 6-8 December 2006.

Turnhout, E., Stuiver, M., Klostermann, J., Harms, B. and Leeuwis, C. (2013) New roles of science in society: Different repertoires of knowledge brokering, Science and Public Policy, 40: 354-365.

Ulm, S. and Mate, G. (2010), Conflict: how people contest the landscape, Queensland Historical Atlas, http://www.qhatlas.com.au/photograph/anti-recycled-watercampaign-toowoomba. Accessed 12 May 2014.

van Buuren, A. and Edelenbos, J. (2004) Conflicting knowledge: Why is joint knowledge production such a problem?, Science and Public Policy, 31: 289299.

van Vuuren, K. (2009) Press bias and local power in the Toowoomba water referendum. Communication, Politics and Culture, 42(1): 55-73.

Walton, A. and Hume, M. (2011) Creating positive habits in water conservation: the case of the Queensland Water Commission and the Target 140 campaign. International Journal of Nonprofit and Voluntary Sector Marketing, 16(3): 215224.

Weingart, P . (1999) Scientific expertise and political accountability: paradoxes of science in politics, Science and Public Policy, 26: 151-161. 